\title{
Article \\ Influence of Polymorphism on the NFkB1 Gene (rs28362491) on the Susceptibility to Sarcopenia in the Elderly of the Brazilian Amazon
}

\author{
Esdras E. B. Pereira ${ }^{1}\left(\mathbb{D}\right.$, Darlen C. de Carvalho ${ }^{2}$, Luciana P. C. Leitão ${ }^{2}{ }^{(D}$, Juliana C. G. Rodrigues ${ }^{2}(\mathbb{D}$, \\ Antônio A. C. Modesto ${ }^{1} \mathbb{D}$, Evitom C. de Sousa ${ }^{3} \mathbb{D}$, Sidney E. B. dos Santos ${ }^{1,2}$, Marianne R. Fernandes ${ }^{2} \mathbb{D}$ and \\ Ney P. C. dos Santos $1,2, *$
}

check for updates

Citation: Pereira, E.E.B.; de Carvalho, D.C.; Leitão, L.P.C.; Rodrigues, J.C.G.; Modesto, A.A.C.; de Sousa, E.C.; dos Santos, S.E.B.; Fernandes, M.R.; dos Santos, N.P.C. Influence of Polymorphism on the NFkB1 Gene (rs28362491) on the Susceptibility to Sarcopenia in the Elderly of the Brazilian Amazon. J. Pers. Med. 2021, 11, 1045. https:// doi.org/10.3390/jpm11101045

Academic Editor: Jasminka Ilich-Ernst

Received: 15 August 2021 Accepted: 28 September 2021 Published: 19 October 2021

Publisher's Note: MDPI stays neutral with regard to jurisdictional claims in published maps and institutional affiliations.

Copyright: (c) 2021 by the authors. Licensee MDPI, Basel, Switzerland. This article is an open access article distributed under the terms and conditions of the Creative Commons Attribution (CC BY) license (https:// creativecommons.org/licenses/by/ $4.0 /)$.
1 Laboratory of Human and Medical Genetics, Institute of Biological Science, Federal University of Pará, Belém 66077-830, Pará, Brazil; esdrasedgarbp@gmail.com (E.E.B.P.); antonioacm@ufpa.br (A.A.C.M.); sidneysantos@ufpa.br (S.E.B.d.S.)

2 Oncology Research Center, Federal University of Pará, Belém 66073-005, Pará, Brazil; darlen.c.cavalho@gmail.com (D.C.d.C.); colaresluciana@gmail.com (L.P.C.L.); julianacgrodrigues@gmail.com (J.C.G.R.); fernandesmr@yahoo.com.br (M.R.F.)

3 Resistance Exercise and Health Laboratory, State University of Pará, Belém 66095-049, Pará, Brazil; evitomuepa@gmail.com

* Correspondence: npcsantos.ufpa@gmail.com

\begin{abstract}
Background: Sarcopenia is a disease characterized by progressive reduction in muscle mass and strength or function. Although it is known that sarcopenia may be associated with environmental factors, studies suggest the identification of genes related to skeletal muscle maintenance that explain the susceptibility to the disease. Objective: To analyze the influence of NFkB1 gene polymorphism on susceptibility to sarcopenia in the elderly. Methods: This is a case-control study, which included 219 elderly people, 74 elderly people with sarcopenia, and 145 without sarcopenia. Samples were analyzed for NFkB1 gene polymorphism (rs28362491), genotyped in PCR, and followed by fragment analysis. To avoid misinterpretation due to population substructure, we applied a previously developed set of 61 informative ancestral markers that were genotyped by multiplex PCR. We used logistic regression to identify differences in genotypic frequencies between elderly people with and without sarcopenia. Results: It was observed that the NFkB1 gene polymorphism presented frequencies of $24 \%, 50 \%$, and $26 \%$ for the genotype DEL/DEL, DEL/INS, and INS/INS, respectively. Furthermore, elderly individuals with the INS/INS genotype had increased chances ( $p=0.010$; OR:2.943; 95\%CI:1.301-6.654) for the development of sarcopenia. Conclusion: The INDEL polymorphism of the NFkB1 gene (rs28362491) may influence the susceptibility to sarcopenia in the elderly in elderly people in the Amazon.
\end{abstract}

Keywords: skeletal muscle; genetic biomarkers; NFkB1; sarcopenia

\section{Introduction}

Sarcopenia is a progressive degenerative disease characterized by loss of skeletal muscle mass and reduced function [1]. Worldwide, this disease is common between $9.9 \%$ and $40.4 \%$ of people over 60 years, depending on the population investigated and the criteria used [2]. In Brazil, this prevalence is $17 \%$ among the elderly [3]. The clinical consequences of sarcopenia include the risk of falls, fractures, loss of function, frailty, and increased mortality, generating significant personal and socioeconomic costs, and it is considered a public health problem that needs to be identified early [4-6].

The pathophysiology of sarcopenia is complex and can be attributed to a variety of factors, including oxidative stress, inflammation, apoptosis, and mitochondrial dysregulation [7]. The disease is also associated with environmental factors, such as physical activity and diet, and may have specific genetic influences, related to skeletal muscle maintenance, 
which may explain the variability of inter-individual characteristics related to muscle mass and strength [8].

This has motivated studies that suggest the importance of determining the genetic factors that are associated with aging and that can modulate skeletal muscle phenotypes in the elderly and the unfavorable genotypes associated with accelerated sarcopenia [9]. These would be biomarkers, possibly used in screening, diagnosis, staging, and sarcopenia prognosis [10-12].

Most studies involving genetic susceptibility to sarcopenia explore genes for hormones, receptors, cytokines, growth factors, structural factors, and metabolism $[10,11,13]$. Despite this, little progress has been made in identifying the specific genetic influences on sarcopenia. Furthermore, there are few studies that aim to predict the risk of sarcopenia based on single nucleotide polymorphisms (SNPs) [8]. Thus, further studies in different populations are needed to understand the genetic influence on sarcopenia.

A common element of these pathways is nuclear factor kappa B (NFkB), a family of pleiotropic transcription factors, NFkB1 (p50/p105), NFkB2 (p52/p100), RelA (p65), c-Rel and Rel B, which regulate other myogenic transcription factors such as MyoD, MURF-1, and MAXbx involved in the development of sarcopenia [14-16].

The NFkB1 gene is located on chromosome 4q24 and consists of 24 exons [16]. The NFkB1 gene polymorphism (rs28362491) occurs between activator protein 1 (AP-1) and the $\mathrm{KB}$ binding site and has been associated with diseases of aging, such as inflammatory diseases, believed to also influence longevity [17-20]. Therefore, the aim of this study was to investigate possible associations between NFkB1 gene polymorphism (rs28362491) and susceptibility to sarcopenia in the elderly people in the Amazon.

\section{Methods}

\subsection{Ethical Conformity}

The study was approved by the Research Ethics Committees of the Oncology Research Center, under protocol 927.808/2014, and by the João de Barros Barreto University Hospital, under protocol number $941.207 / 2015$. All participants signed an informed consent form.

\subsection{Case and Control}

Participants were randomly selected from two public health care centers in the city of Belém do Pará, in the Brazilian Amazon, in a retrospective case-control study design. The 219 individuals were 60 years old or older, of both sexes, not belonging to the same family nucleus, and of the same socioeconomic level. Two groups were structured: 74 patients with sarcopenia (Case Group) and 145 patients without any type of sarcopenia (Control Group).

\subsection{Sarcopenia Assessment}

The sarcopenia diagnosis was based on the EWGSOP algorithm, following two criteria: mass reduction and physical performance [21]. The equation by Lee et al. [22] was used to estimate total muscle mass $(\mathrm{MMT}): \mathrm{MMT}=(0.244 \times$ body weight $)+(7.8 \times$ height $)+$ $(6.6 \times$ gender $)-(0.098 \times$ age $)+($ race -3.3$)$. The number 0 was assigned for women and 1 for men, -1.2 for Asians, 1.4 for blacks, and 0 for whites. The race variable was based on the predominance of genomic ancestry. This equation was validated for the Brazilian population using DEXA as the "gold standard". The equation was fitted by dividing by height squared, creating a total muscle mass index (TMMI). The cutoff point used to determine reduced muscle mass was $\leq 6.75 \mathrm{~kg} / \mathrm{m}^{2}$ for women and $\leq 10.75 \mathrm{~kg} / \mathrm{m}^{2}$ for men Physical performance was assessed by mobility, using the 6-m Gait Speed Test (TVM6) and the cutoff point of $<0.8 \mathrm{~m} / \mathrm{s}$ indicating participants with low physical performance [1,21].

\subsection{Clinical Assessment}

The clinical assessment consisted of scales and quantitative tests. The clinical characterization of the sample included sex, age, lifestyle (alcoholism, smoking, and sedentary lifestyle), present comorbidities, nutritional status, and a screening questionnaire for sar- 
copenia (SARC-CalF) and anthropometry. The presence of comorbidities was assessed using the Charlson Comorbidity Index (ICC) [23]. Nutritional status was assessed by the Mini Nutritional Assessment (MAN) [24]. The SARC-CalF questionnaire consists of 6 items questioning strength, help to walk, stand up from a chair, climbing stairs, falls, and calf perimeter [25]. Anthropometry includes measurement of weight $(\mathrm{kg})$, height (m), body mass index $\left(\mathrm{kg} / \mathrm{m}^{2}\right)$, and calf perimeter $(\mathrm{cm})$.

\subsection{DNA Extraction and Quantification}

Extraction of genomic DNA from peripheral blood leukocytes was conducted using a Mini Spin Plus Kit (P.250, Biopur, Biometrix) according to the manufacturer's recommendations. DNA concentration and purity were measured with a NanoDrop 1000 spectrophotometer (Thermo Scientific NanoDrop 1000; NanoDrop Technologies).

\subsection{Genotyping}

The NFkB1 gene polymorphism (rs28362491) was genotyped by a multiplex PCR reaction followed by capillary electrophoresis. For the amplifications, $0.5 \mu \mathrm{L}$ of the QIAGEN Multiplex PCR Kit (QIAGEN), 1.0 $\mu \mathrm{L}$ of Q-solution, $1.0 \mu \mathrm{L}$ of Primer Mix, 2.0 $\mu \mathrm{L}$ of water, and $20 \mathrm{ng}$ of DNA were used. PCR was performed following the following protocol: an initial denaturation at $95^{\circ} \mathrm{C}$ for $15 \mathrm{~min}, 35$ cycles at $94{ }^{\circ} \mathrm{C}$ for $45 \mathrm{~s}, 60^{\circ} \mathrm{C}$ for $90 \mathrm{~s}$, and $72{ }^{\circ} \mathrm{C}$ for $60 \mathrm{~s}$, followed by a final extension of $70{ }^{\circ} \mathrm{C}$ for $30 \mathrm{~min}$. Analysis of the PCR amplicons was performed from an electrophoresis using the ABI Prism 3130 sequencer and GeneMapper ID v.3.2 software.

\subsection{Hardy-Weinberg Equilibrium Analysis (HWE)}

The allelic and genotypic frequency of the polymorphism was determined by direct counting of alleles, and then Hardy-Weinberg equilibrium (HWE) was calculated using Arlequin 3.5.1.2 software. The individual proportions of European, African, and Amerindian genetic ancestry were estimated using Structure 2.3.3 software. It was evidenced that the polymorphism was present in the HWE.

\subsection{Genetic Ancestrality Analysis}

Genotyping was performed to analyze the ancestry of the samples, performed according to Ramos et al. [26], using 61 informative markers of autosomal ancestry in three multiplex PCR reactions. Amplicons were analyzed by electrophoresis using the ABI Prism 3130 sequencer and GeneMapper ID v.3.2 software. The individual proportions of European, African, and Amerindian genetic ancestry were estimated using Structure v.2.3.3 software, assuming three parental populations.

\subsection{Statistical Analysis}

For the comparative analysis between the studied groups, Pearson's Chi-Square Test was applied, for categorical variables, and the Mann-Whitney test for non-parametric quantitative variables. To analyze the risk of polymorphisms on sarcopenia, a logistic regression controlled by the covariates age, comorbidity, sedentary lifestyle and nutritional status was performed. All statistical analyses were performed using the statistical package of the SPSS 20.0 software, respecting the significance level of $5 \%$ ( $p$-value $\leq 0.05$ ).

\section{Results}

A prevalence of sarcopenia of $34 \%$ of the elderly evaluated was observed, being more frequent in women $(56.8 \%)$, aged over 70 years $(56.8 \%)$, with a greater number of comorbidities, with a history of sedentary lifestyle $(90.5 \%)$, and possessing a predominantly European ancestry. It was evident that the demographic and clinical characteristics between the groups differed significantly for age $(p=0.014)$, comorbidities $(p<0.0001)$, sedentary lifestyle $(p<0.0001)$, nutritional status $(p<0.0001)$, and the SARC-CalF score $(p<0.0001)$ (Table 1). 
Table 1. Demographic and clinical characteristics of the investigated groups.

\begin{tabular}{|c|c|c|c|}
\hline Characteristics & Case $(n=74)$ & Control $(n=145)$ & $p$-Value \\
\hline \multicolumn{4}{|l|}{ Sex } \\
\hline Male & $32(43.2 \%)$ & $51(35.2 \%)$ & \multirow{2}{*}{$0.2440^{a}$} \\
\hline Female & $42(56.8 \%)$ & $94(64.8 \%)$ & \\
\hline \multicolumn{4}{|l|}{ Age } \\
\hline$\leq 70$ years & $32(43.2 \%)$ & $88(60.7 \%)$ & \multirow{2}{*}{$0.0140^{a, *}$} \\
\hline$>70$ years & $42(56.8 \%)$ & $57(39.3 \%)$ & \\
\hline \multicolumn{4}{|l|}{ Charlson Index (Score) } \\
\hline Median (p25\%-p75\%) & $5.0(4.0-7.0)$ & $3.0(2.0-5.0)$ & $<0.0001^{\mathrm{b}, *}$ \\
\hline \multicolumn{4}{|l|}{ Lifestyle } \\
\hline Smoking & $46(62.2 \%)$ & $74(51.0 \%)$ & $0.1180^{a}$ \\
\hline Alcoholism & $34(45.9 \%)$ & $74(51.0 \%)$ & $0.4760^{\mathrm{a}}$ \\
\hline Sedentary lifestyle & $67(90.5 \%)$ & $50(34.5 \%)$ & $<0.0001^{a, *}$ \\
\hline \multicolumn{4}{|l|}{ Nutritional Status (NMA) } \\
\hline Normal & $49(66.2 \%)$ & $139(95.9 \%)$ & \multirow{2}{*}{$<0.0001^{a, *}$} \\
\hline Malnourished & $25(33.8 \%)$ & $6(4.1 \%)$ & \\
\hline \multicolumn{4}{|l|}{ SARC-CalF (Score) } \\
\hline Median (p25\%-p75\%) & $16.0(12.0-18.0)$ & $10.0(0.0-10.0)$ & $<0.0001^{b, *}$ \\
\hline \multicolumn{4}{|l|}{ Ancestry } \\
\hline European & $0.451 \pm 0.178$ & $0.456 \pm 0.170$ & $0.9530^{b}$ \\
\hline Amerindian & $0.316 \pm 0.151$ & $0.299 \pm 0.149$ & $0.4200^{b}$ \\
\hline African & $0.232 \pm 0.123$ & $0.244 \pm 0.146$ & $0.8470^{b}$ \\
\hline
\end{tabular}

NMA, Nutritional Mini-Assessment; SARC-CalF, Screening Questionnaire for Sarcopenia; p, percentile. ${ }^{a}$ Pearson's Chi-Square test; ${ }^{b}$ Mann-Whitney test; ${ }^{*} p$-value $\leq 0.05$.

Table 2 shows information regarding anthropometry, total muscle mass index, and functional mobility. In anthropometry, it could be observed that the elderly group with sarcopenia was lighter in weight $(p<0.0001)$, with lower BMI $(p<0.0001)$, and lower calf circumference $(p<0.0001)$. In addition, this group also had a lower total muscle mass index $(p<0.0001)$ and lower gait speed $(p<0.0001)$.

Table 2. Anthropometry, total muscle mass index, and functional mobility of the investigated groups.

\begin{tabular}{|c|c|c|c|}
\hline Variables & Case $(n=74)$ & Control $(n=145)$ & $p$-Value ${ }^{\text {a }}$ \\
\hline \multicolumn{4}{|l|}{ Anthropometry } \\
\hline Weight $(\mathrm{kg})$ & $50.99 \pm 11.31$ & $65.99 \pm 11.89$ & $<0.0001 *$ \\
\hline Height (m) & $1.58 \pm 0.09$ & $1.59 \pm 0.09$ & 0.8890 \\
\hline $\operatorname{BMI}\left(\mathrm{kg} / \mathrm{m}^{2}\right)$ & $20.31 \pm 4.52$ & $26.08 \pm 4.57$ & $<0.0001$ * \\
\hline Calf Circumference (cm) & $27.92 \pm 2.09$ & $34.26 \pm 3.00$ & $<0.0001$ * \\
\hline \multicolumn{4}{|c|}{ Total Muscle Mass Index $\left(\mathrm{kg} / \mathrm{m}^{2}\right)$} \\
\hline Mean $( \pm$ sd $)$ & $7.17 \pm 1.69$ & $8.50 \pm 1.59$ & $<0.0001 *$ \\
\hline \multicolumn{4}{|l|}{ Functional Mobility } \\
\hline Gait Speed (m/s) & $0.30 \pm 0.19$ & $0.60 \pm 0.32$ & $<0.0001$ * \\
\hline
\end{tabular}

It was evidenced that polymorphism was present in the HWE ( $p$-value 0.955). The results of the logistic regression analysis showed that the INS/INS genotype of the NFkB1 polymorphism (rs28362491) increased the risk of sarcopenia compared to the other genotypes (OR: 2.943; 95\% CI: 1.301-6.654). As for allele frequency, the INS allele of this polymorphism increased the risk of sarcopenia compared to the DEL allele (OR: 1.932; 95\%CI: 1.187-3.145) (Table 3).

Comparisons of total muscle mass index (TMMI), calf circumference, and gait speed among the three NFKB1 genotypes (rs28362491) shown in Table 4 show that the calf circumference was significantly smaller among the elderly with the INS/INS genotype ( $p$-value: 0.013 ). The total muscle mass index and gait speed were also lower in the elderly with the INS/INS genotype; however, this difference was not significant (Table 4). 
Table 3. Genotypic distribution of the NFkB1 gene polymorphism (rs28362491) in the investigated groups.

\begin{tabular}{ccccc}
\hline Genotype & Case $(\boldsymbol{n}=\mathbf{7 4})$ & Control $(\boldsymbol{n}=\mathbf{1 4 5})$ & $\boldsymbol{p}$-Value ${ }^{\text {a }}$ & OR (95\% CI) \\
\hline NFkB1 (rs28362491) & & & & INS/INS vs. Others: \\
DEL/DEL & $15(20.3 \%)$ & $37(25.5 \%)$ & $0.010^{*}$ & $2.943(1.301-6.654)$ \\
DEL/INS & $30(40.5 \%)$ & $79(54.5 \%)$ & & $1.932(1.187-3.145)$ \\
INS/INS & $29(39.2 \%)$ & $29(20.0 \%)$ & $0.008 *$ & $153(52.8 \%)$ \\
Allele DEL & $60(40.5 \%)$ & $137(47.2 \%)$ & & \\
Allele INS & $88(59.5 \%)$ & & & \\
\hline
\end{tabular}

INS/INS, insertion/insertion; DEL/INS, deletion/insertion; DEL/DEL, deletion/deletion; OR, odds ratio; CI, confidence interval; ${ }^{\text {logistic }}$ regression adjusted for age, comorbidities, sedentary lifestyle, and nutritional status; ${ }^{*} p$-value $\leq 0.05$.

Table 4. Comparison of total muscle mass index, calf circumference, and gait speed among the NFkB1 genotypes (rs28362491) of the investigated groups.

\begin{tabular}{|c|c|c|c|c|c|}
\hline \multirow{2}{*}{ Variables } & \multicolumn{4}{|c|}{ NFkB1 Genotypes (rs28362491) } & \multirow{2}{*}{$\begin{array}{c}\text { INS/INS vs. Others } \\
p \text {-Value }{ }^{\text {a }}\end{array}$} \\
\hline & $\begin{array}{l}\text { DEL/DEL } \\
(n=52)\end{array}$ & $\begin{array}{l}\text { DEL/INS } \\
(n=109)\end{array}$ & $\begin{array}{c}\text { INS/INS } \\
(n=58)\end{array}$ & $\begin{array}{c}\text { DEL/DEL+DEL/INS } \\
(n=161)\end{array}$ & \\
\hline \multicolumn{6}{|l|}{ TMMI (kg/m²) } \\
\hline Mean $( \pm s d)$ & $8.39 \pm 1.58$ & $8.00 \pm 1.77$ & $7.84 \pm 1.82$ & $8.14 \pm 1.71$ & 0.227 \\
\hline \multicolumn{6}{|c|}{ Calf Circumference (cm) } \\
\hline Mean $( \pm \mathrm{sd})$ & $31.98 \pm 3.09$ & $32.71 \pm 4.23$ & $31.05 \pm 2.29$ & $32.48 \pm 3.91$ & $0.013 *$ \\
\hline \multicolumn{6}{|l|}{ Gait Speed (m/s) } \\
\hline Mean $( \pm \mathrm{sd})$ & $0.43 \pm 0.27$ & $0.55 \pm 0.34$ & $0.46 \pm 0.30$ & $0.51 \pm 0.33$ & 0.269 \\
\hline
\end{tabular}

TMMI, total muscle mass index; INS/INS, insertion/insertion; DEL/INS, deletion/insertion; DEL/DEL, deletion/deletion; sd, standard deviation; ${ }^{\text {a }}$ Mann-Whitney test; ${ }^{*} p$-value $\leq 0.05$.

\section{Discussion}

Sarcopenia is a common syndrome among the elderly, and its prevalence varies significantly worldwide $[27,28]$. In the present study, in the Amazon region, the prevalence of sarcopenia was $34 \%$, similar to a study carried out in the southern region of Brazil, which identified a prevalence of $33.3 \%$ among the elderly [29]. However, both are superior to what was observed by Diz et al. [3], who identified in their review an average prevalence of $17 \%$ of sarcopenia among elderly Brazilians. These distinctions must be analyzed with caution, due to the use of different methods for assessing sarcopenia between studies and differences in the characteristics of the populations investigated.

In this study, most elderly people with sarcopenia were over 70 years of age (56.8\%) and were female (56.8\%). According to Cruz-Jentoft et al. [21], the frequency of sarcopenia varies from 5 to $13 \%$ in the elderly aged between 60 and 70 years and increases to $11-50 \%$ for those with more advanced age, which may be associated with the identification of a higher prevalence of sarcopenia in this population.

As in the rest of the world, in Brazil the life expectancy of the female population is greater than that of men, causing them to experience more geriatric syndromes, which may justify sarcopenia being more prevalent in this group [3,30,31]. Furthermore, the emergence of sarcopenia in women seems to be associated with menopause, which causes hormonal changes, which modify the maintenance of muscle tissue [32]. This reduction in sex hormones is more accelerated among women than men [27].

Susceptibility to sarcopenia includes constitutional risk factors and lifestyle and health conditions. Among the constitutional factors are female gender and genetic propensity [33]. Genetic influence explains a significant fraction of the inter-individual variability of sarcopenia, which is driven by genes involved in pathways of metabolism, DNA damage repair, oxidative stress, inflammatory and immune responses, and programmed cell death [34].

In the present study, the analysis of the NFkB1 gene polymorphism (rs28362491) showed relevant results. The polymorphism presented frequencies of $24 \%, 50 \%$, and $26 \%$ for the genotype DEL/DEL, DEL/INS, and INS/INS, respectively. Elderly individuals with the INS/INS genotype had increased chances ( $p=0.010$; OR: 2.943; 95\%CI: 1.301-6.654) 
for the development of sarcopenia. Therefore, individuals homozygous for this insertion in the NFkB1 gene have an approximately three-fold increased risk for the development of sarcopenia. In addition, the elderly with this genotype had smaller calf circumference $(p=0.013)$, which also indicates reduced muscle mass.

Oxidative stress, immune response and chronic inflammation influence the maintenance of skeletal muscle, affecting the balance between protein synthesis and breakdown, inducing muscle wasting [14]. The INS/INS genotype of the rs28362491 polymorphism of the NFkB1 gene has been related to the risk of developing inflammatory diseases associated with altered immune response [16]. The likely mechanism that explains this association may be related to the increased expression and activity of NFkB1, where the INS allele is supposedly associated with increased promoter activity and increased expression of NFkB mRNA [34].

The increased activity of NFkB1 promotes the expression of proteins of the ubiquitinproteasome system, involved in the breakdown of muscle proteins, in the increased expression of molecules related to inflammation, and in the influence of the myogenic differentiation process, which is necessary for the regeneration of skeletal muscles $[35,36]$. These pathways, when activated, favor chronic inflammation, sarcopenia, and the frailty syndrome [37-39].

This shows that sarcopenia is certainly related to genetic and environmental mechanisms, which manifest as atrophy, reduced endurance, and loss of muscle strength, which culminate in functional disabilities [40]. This is because joint movement needs preserved muscle strength to maintain gait, limb movements, and actions against gravity, such as sitting and standing, necessary for activities of daily living [41,42].

We believe that the results of association of the NFKB1 gene polymorphism (rs28362491) with sarcopenia observed in the present study can also be found in other Brazilian regions, respecting the constitutional characteristics of populations between regions. According to Souza et al. [43] the proportions of European, African, and Amerindian genomic ancestry are $68.1 \%, 19.6 \%$, and $11.6 \%$, respectively, while in the states of the Amazon region, these respective proportions are $52.6 \%, 19.8 \%$, and $27.7 \%$, revealing that the Amazon region has a greater contribution from Amerindian genomic ancestry, similar to what was observed in the present study.

In the world, as it is a germline structural variant, similar results of this association of NFKB1 gene polymorphism (rs28362491) with sarcopenia can be found, considering that this polymorphism has already been described in non-Brazilian populations [17-20]. There are already studies showing the association of this gene with the muscle [14-16]. However, our study is the first to show an association of this polymorphism with sarcopenia.

The NFkB1 pathway is not only activated in aging, but directly contributes to agerelated pathologies such as sarcopenia. Knowledge of genetic polymorphisms, present in this and other pathways, is important in translational research for sarcopenia, as they provide information for the identification of susceptibility, risk stratification, and potential therapeutic targets, whether by pharmacological or non-pharmacological measures, which aim to maintain or increase the mass, strength, and function of the skeletal muscle, thus preserving the functional capacities and independence of the elderly.

\section{Conclusions}

In conclusion, the NFkB1 gene variant (rs28362491) was associated with the risk of developing sarcopenia in elderly people in the Amazon. Elderly people with the INS/INS genotype were almost three times more susceptible to developing the disease. This indicates its potential additional use in screening for sarcopenia in the elderly population, which may facilitate the targeting of prevention, control, and treatment strategies for the disease. 
Author Contributions: E.E.B.P. designed the study, processed the data, and wrote the article. D.C.d.C. contributed to data analysis. L.P.C.L. contributed to the writing of the article. J.C.G.R. contributed to the writing of the article. A.A.C.M. contributed to the genotyping and data analysis. E.C.d.S. contributed to data collection. S.E.B.d.S., M.R.F. and N.P.C.d.S. were the project coordinators. All authors have read and agreed to the published version of the manuscript.

Funding: Coordenação de Aperfeiçoamento de Pessoal de Nível Superior (CAPES); Fundação Amazônia de Amparo a Estudos e Pesquisas (FAPESPA); and Universidade Federal do Pará (UFPA).

Institutional Review Board Statement: The study was conducted according to the guidelines of the Declaration of Helsinki, and approved by the Research Ethics Committees of the Oncology Research Center of UFPA, under protocol number 927.808/2014, and by the João de Barros Barreto University Hospital of UFPA, under protocol number 941.207/2015. All participants signed an informed consent form.

Informed Consent Statement: Informed consent was obtained from all subjects involved in the study.

Acknowledgments: We acknowledge the Universidade Federal do Pará (UFPA); Faculty of Medicine (FAMED/UFPA); Oncology Research Center (NPO/UFPA); Graduate Program in Genetics and Molecular Biology (PPGBM/UFPA); Human and Medical Genetics Laboratory (LGHM/UFPA); João de Barros Barreto University Hospital (HUJBB/UFPA); and Resistance Exercise and Health Laboratory (LERES/UEPA).

Conflicts of Interest: The authors declare that they have no competing interests.

\section{References}

1. Cruz-Jentoft, A.J.; Bahat, G.; Bauer, J.; Boirie, Y.; Bruyère, O.; Cederholm, T.; Cooper, C.; Landi, F.; Rolland, Y.; Sayer, A.A.; et al. Sarcopenia: Revised European consensus on definition and diagnosis. Age Ageing 2019, 48, 16-31. [CrossRef]

2. Mayhew, A.J.; Amog, K.; Phillips, S.; Parise, G.; McNicholas, P.D.; de Souza, R.J.; Thabane, L.; Raina, P. The prevalence of sarcopenia in community-dwelling older adults, an exploration of differences between studies and within definitions: A systematic review and meta-analyses. Age Ageing 2018, 48, 48-56. [CrossRef]

3. Diz, J.B.M.; Leopoldino, A.A.O.; Moreira, B.D.S.; Henschke, N.; Dias, R.C.; Pereira, L.S.M.; Oliveira, V.C. Prevalence of sarcopenia in older Brazilians: A systematic review and meta-analysis. Geriatr. Gerontol. Int. 2016, 17, 5-16. [CrossRef]

4. Hirschfeld, H.P.; Kinsella, R.; Duque, G. Osteosarcopenia: Where bone, muscle, and fat collide. Osteoporos. Int. 2017, 28, 2781-2790. [CrossRef]

5. Falcon, L.J.; Harris-Love, M.O. Sarcopenia and the New ICD-10-CM Code: Screening, Staging, and Diagnosis Considerations. Fed. Pract. 2017, 34, 24-32. [CrossRef]

6. Tosato, M.; Marzetti, E.; Cesari, M.; Savera, G.; Miller, R.R.; Bernabei, R.; Landi, F.; Calvani, R. Measurement of muscle mass in sarcopenia: From imaging to biochemical markers. Aging Clin. Exp. Res. 2017, 29, 19-27. [CrossRef]

7. Yao, X.; Yang, L.; Li, M.; Xiao, H. Relationship of vitamin D receptor gene polymorphism with sarcopenia and muscle traits based on propensity score matching. J. Clin. Lab. Anal. 2020, 34, e23485. [CrossRef] [PubMed]

8. Urzi, F.; Pokorny, B.; Buzan, E. Pilot Study on Genetic Associations with Age-Related Sarcopenia. Front. Genet. 2021, 11, 615238. [CrossRef] [PubMed]

9. Tacutu, R.; Craig, T.; Budovsky, A.; Wuttke, D.; Lehmann, G.; Taranukha, D.; Costa, J.; Fraifeld, V.E.; de Magalhaes, J.P. Human Ageing Genomic Resources: Integrated databases and tools for the biology and genetics of ageing. Nucleic Acids Res. 2012, 41, D1027-D1033. [CrossRef] [PubMed]

10. Roth, S.M. Genetic aspects of skeletal muscle strength and mass with relevance to sarcopenia. Bonekey Rep. 2012, 1, 58. [CrossRef]

11. Tan, L.-J.; Liu, S.-L.; Lei, S.-F.; Papasian, C.J.; Deng, H.-W. Molecular genetic studies of gene identification for sarcopenia. Qual. Life Res. 2011, 131, 1-31. [CrossRef] [PubMed]

12. Calvani, R.; Marini, F.; Cesari, M.; Tosato, M.; Picca, A.; Anker, S.D.; Von Haehling, S.; Miller, R.R.; Bernabei, R.; Landi, F.; et al. Biomarkers for physical frailty and sarcopenia. Aging Clin. Exp. Res. 2017, 29, 29-34. [CrossRef] [PubMed]

13. Karasik, D.; Cohen-Zinder, M. The genetic pleiotropy of musculoskeletal aging. Front. Physiol. 2012, 3, 303. [CrossRef] [PubMed]

14. Meng, S.-J.; Yu, L.-J. Oxidative Stress, Molecular Inflammation and Sarcopenia. Int. J. Mol. Sci. 2010, 11, 1509-1526. [CrossRef] [PubMed]

15. Patel, H.P.; Al-Shanti, N.; Davies, L.C.; Barton, S.; Grounds, M.; Tellam, R.; Stewart, C.; Cooper, C.; Sayer, A.A. Lean Mass, Muscle Strength and Gene Expression in Community Dwelling Older Men: Findings from the Hertfordshire Sarcopenia Study (HSS). Calcif. Tissue Int. 2014, 95, 308-316. [CrossRef]

16. Yenmis, G.; Oner, T.; Cam, C.; Koc, A.; Kucuk, O.S.; Yakicier, M.C.; Dizman, D.; Sultuybek, G.K. Association ofNFKB1 and NFKBIAPolymorphisms in Relation to Susceptibility of Behçet's Disease. Scand. J. Immunol. 2014, 81, 81-86. [CrossRef] [PubMed] 
17. Yang, Y.-N.; Zhang, J.-Y.; Ma, Y.-T.; Xie, X.; Li, X.-M.; Liu, F.; Chen, B.-D.; Dong, X.-H.; Zheng, Y.-Y.; Pan, S.; et al. -94 ATTG Insertion/Deletion Polymorphism of theNFKB1Gene Is Associated with Coronary Artery Disease in Han and Uygur Women in China. Genet. Test. Mol. Biomark. 2014, 18, 430-438. [CrossRef]

18. Chen, L.; Cai, P.; Liang, H. Association of the genetic polymorphisms of NFKB1 with susceptibility to ovarian cancer. Genet. Mol. Res. 2015, 14, 8273-8282. [CrossRef]

19. Lai, H.-M.; Li, X.-M.; Yang, Y.-N.; Ma, Y.-T.; Xu, R.; Pan, S.; Zhai, H.; Liu, F.; Chen, B.-D.; Zhao, Q. Genetic Variation in NFKB1 and NFKBIA and Susceptibility to Coronary Artery Disease in a Chinese Uygur Population. PLoS ONE 2015, 10, e0129144. [CrossRef]

20. Wang, Y.; Chen, L.; Pan, L.; Xue, J.; Yu, H. The association between NFKB1-94ins/del ATTG polymorphism and non-small cell lung cancer risk in a Chinese Han population. Int. J. Clin. Exp. Med. 2015, 8, 8153-8157.

21. Cruz-Jentoft, A.J.; Baeyens, J.P.; Bauer, J.M.; Boirie, Y.; Cederholm, T.; Landi, F.; Martin, F.C.; Michel, J.-P.; Rolland, Y.; Schneider, S.; et al. Sarcopenia: European consensus on definition and diagnosis: Report of the European Working Group on Sarcopenia in Older People. Age Ageing 2010, 39, 412-423. [CrossRef] [PubMed]

22. Lee, R.C.; Wang, Z.; Heo, M.; Ross, R.; Janssen, I.; Heymsfield, S.B. Total-body skeletal muscle mass: Development and cross-validation of anthropometric prediction models. Am. J. Clin. Nutr. 2000, 72, 796-803. [CrossRef] [PubMed]

23. Marchena-Gómez, J.; Acosta-Merida, M.A.; Hemmersbach-Miller, M.; Conde-Martel, A.; Roque-Castellano, C.; HernandezRomero, J. The Age-Adjusted Charlson Comorbidity Index as an Outcome Predictor of Patients with Acute Mesenteric Ischemia. Ann. Vasc. Surg. 2009, 23, 458-464. [CrossRef] [PubMed]

24. Serrano-Urrea, R.; Garcia-Meseguer, M.J. Malnutrition in an elderly population without cognitive impairment living in nursing homes in Spain: Study of prevalence using the Mini Nutritional Assessment test. Gerontology 2013, 59, 490-498. [CrossRef]

25. Bahat, G.; Oren, M.M.; Yilmaz, O.; Kiliç, C.; Aydin, K.; Karan, M.A. Comparing SARC-F with SARC-CalF to Screen Sarcopenia in Community Living Older Adults. J. Nutr. Health Aging 2018, 22, 1034-1038. [CrossRef] [PubMed]

26. Ramos, B.R.D.A.; D’Elia, M.P.B.; Amador, M.A.T.; Santos, N.P.C.; Santos, S.E.B.; Castelli, E.D.C.; Witkin, S.S.; Miot, H.A.; Miot, L.D.B.; da Silva, M.G. Neither self-reported ethnicity nor declared family origin are reliable indicators of genomic ancestry. Genetica 2016, 144, 259-265. [CrossRef]

27. Shafiee, G.; Keshtkar, A.; Soltani, A.; Ahadi, Z.; Larijani, B.; Heshmat, R. Prevalence of sarcopenia in the world: A systematic review and meta- analysis of general population studies. J. Diabetes Metab. Disord. 2017, 16, 1-10. [CrossRef] [PubMed]

28. Dhillon, R.J.; Hasni, S. Pathogenesis and Management of Sarcopenia. Clin. Geriatr. Med. 2017, 33, 17-26. [CrossRef]

29. Pelegrini, A.; Mazo, G.Z.; Pinto, A.D.A.; Benedetti, T.R.B.; Silva, D.A.S.; Petroski, E.L. Sarcopenia: Prevalence and associated factors among elderly from a Brazilian capital. Fisioter. Mov. 2018, 31, e003102. [CrossRef]

30. Moreira, V.G.; Perez, M.; Lourenço, R.A. Prevalence of sarcopenia and its associated factors: The impact of muscle mass, gait speed, and handgrip strength reference values on reported frequencies. Clinics 2019, 74, e477. [CrossRef]

31. Alodhayani, A.A. Sex-specific differences in the prevalence of sarcopenia among pre-frail community-dwelling older adults in Saudi Arabia. Saudi J. Biol. Sci. 2021, 28, 4005-4009. [CrossRef] [PubMed]

32. Geraci, A.; Calvani, R.; Ferri, E.; Marzetti, E.; Arosio, B.; Cesari, M. Sarcopenia and Menopause: The Role of Estradiol. Front. Endocrinol. 2021, 12, 682012. [CrossRef] [PubMed]

33. Hairi, N.N.; Bulgiba, A.; Hiong, T.G.; Mudla, I. Sarcopenia in Older People. In Geriatrics Craig Atwood; Atwood, C., Ed.; IntechOpen: Rijeka, Croatia, 2012; pp. 29-40. [CrossRef]

34. Kolovou, G.; Kolovou, V.; Vasiliadis, I.; Giannakopoulou, V.; Mihas, C.; Bilianou, H.; Kollia, A.; Papadopoulou, E.; Marvaki, A.; Goumas, G.; et al. The Frequency of 4 Common Gene Polymorphisms in Nonagenarians, Centenarians, and Average Life Span Individuals. Angiology 2013, 65, 210-215. [CrossRef] [PubMed]

35. Romanick, M.; Thompson, L.V.; Brown-Borg, H.M. Murine models of atrophy, cachexia, and sarcopenia in skeletal muscle. Biochim. Biophys. Acta 2013, 1832, 1410-1420. [CrossRef]

36. Li, H.; Malhotra, S.; Kumar, A. Nuclear factor-kappa B signaling in skeletal muscle atrophy. J. Mol. Med. 2008, 86, 1113-1126. [CrossRef] [PubMed]

37. Ghosh, S.; Lertwattanarak, R.; Garduño, J.D.J.; Galeana, J.J.; Li, J.; Zamarripa, F.; Lancaster, J.L.; Mohan, S.; Hussey, S.; Musi, N. Elevated Muscle TLR4 Expression and Metabolic Endotoxemia in Human Aging. J. Gerontol. Ser. A Boil. Sci. Med. Sci. 2014, 70, 232-246. [CrossRef] [PubMed]

38. Thalacker-Mercer, A.E.; Dell'Italia, L.J.; Cui, X.; Cross, J.M.; Bamman, M.M. Differential genomic responses in old vs. young humans despite similar levels of modest muscle damage after resistance loading. Physiol. Genom. 2010, 40, 141-149. [CrossRef]

39. Buford, T.W.; Cooke, M.B.; Manini, T.M.; Leeuwenburgh, C.; Willoughby, D.S. Effects of Age and Sedentary Lifestyle on Skeletal Muscle NF- B Signaling in Men. J. Gerontol. Ser. A Boil. Sci. Med. Sci. 2010, 65, 532-537. [CrossRef]

40. Di Iorio, A.; Abate, M.; Di Renzo, D.; Russolillo, A.; Battaglini, C.; Ripari, P.; Saggini, R.; Paganelli, R.; Abate, G. Sarcopenia: Age-Related Skeletal Muscle Changes from Determinants to Physical Disability. Int. J. Immunopathol. Pharmacol. 2006, 19, 703-719. [CrossRef]

41. Abate, M.; Di Iorio, A.; Di Renzo, D.; Paganelli, R.; Saggini, R.; Abate, G. Frailty in the elderly: The physical dimension. Eura Medicophys. 2007, 43, 407-415. 
42. Dietzel, R.; Felsenberg, D.; Armbrecht, G. Mechanography performance tests and their association with sarcopenia, falls and impairment in the activities of daily living-A pilot cross-sectional study in 293 older adults. J. Musculoskelet. Neuronal Interact. 2015, 15, 249-256. [PubMed]

43. De Souza, A.M.; Resende, S.S.; De Sousa, T.N.; De Brito, C.F.A. A systematic scoping review of the genetic ancestry of the Brazilian population. Genet. Mol. Biol. 2019, 42, 495-508. [CrossRef] [PubMed] 